\title{
Fidelity and Interseasonal Movements of Purple Finches (Carpodacus purpureus (Gmelin)): Analysis of Band Re-encounter Data
}

\author{
W. Herbert Wilson*, and Bets Brown
}

Department of Biology, Colby College, 5739 Mayflower Hill Drive, Waterville, ME 04901, USA

\begin{abstract}
The Purple Finch (Carpodacus purpureus (Gmelin)) is a migratory fringillid breeding across the northern coniferous forests of North America. Although irruptions occur, little information has been gathered on the movements of individual birds. We used the 19,893 re-encounters of banded birds in the Bird Banding Laboratory database to identify patterns of movements and to examine wintering and breeding site fidelity. After normalizing the data for banding effort, we found that birds banded in the northeastern United States tended to move along the Atlantic Seaboard. Most birds banded in the upper Mid-west also moved along a north-south axis. Purple Finches west of the Sierra Nevada and Cascade Mountains in the far west rarely move east of those mountains. Throughout the range of the species, most movements tend to be along the north-south axis. The re-encounter data indicated a strong level of breeding site and wintering site fidelity with evidence of some year-round fidelity. Analysis of re-encounters as a function of season of banding and season of reencounter demonstrated that birds stayed close to their breeding grounds during the fall before leaving for their wintering areas. Birds departed from the wintering areas early in the spring.
\end{abstract}

Keywords: Distribution, carpodacus, migration, finch.

\section{INTRODUCTION}

Facilitated by the ability to fly, birds can undertake extraordinary interseasonal migrations to nest, find food and avoid climatic extremes [1-3]. Some species migrate thousands of kilometers with notable long-distance migrants including the Sooty Shearwater (Puffinus griseus), Pectoral Sandpiper (Calidris melanotos) and Arctic Tern (Sterna paradesaea) $[1,2]$ Bird censuses and banding stations provide information on the dates and pathways of migrations of particular species. At the level of the species, we have a detailed understanding of the migrations of hundreds of bird species. However, knowledge of the migrations of individuals is sparse. Breeding site fidelity for migratory breeding birds has been documented for a number of species [4-6]. Wintering site fidelity exists for some species but the literature coverage is much thinner $[7,8]$. We have a paucity of information connecting migrants on their wintering grounds to their breeding grounds. Do birds overlapping in their winter range also overlap in their breeding range? Do individual birds demonstrate fidelity to both breeding sites and wintering sites? We provide answers to these questions for one species in this paper.

The Purple Finch (Carpodacus purpureus (Gmelin)) is a moderately common fringillid species that breeds across the northern tier of the United States from Maine to Minnesota and across the southern portions of all the Canadian Provinces [9]. A breeding population is also found along the Pacific coast, west of the Sierra Nevada and Cascade

*Address correspondence to this author at the Department of Biology, Colby College, 5739 Mayflower Hill Drive, Waterville, ME 04901, USA; Tel: 207-859-5739; Fax: 207-859-5705; E-mail: whwilson@colby.edu
Mountains. The Purple Finches in the northernmost portion of the breeding range withdraw in the winter while those in the southern part of the breeding range may be present yearround. Wintering birds may be found throughout most of the eastern United States, occurring as far west as east Texas north to the Dakotas. Some individuals winter along the Pacific coastal region.

Purple Finches are one of the suite of irruptive fringillids popularly called the northern finches. Strong southerly movements occur on a biennial basis in the Purple Finch [1012]. These irruptions are thought to be driven by variation in the production of cone crops of conifers on which the Purple Finches depend. On occasion, an irruption may be remarkably strong [13].

Reports from single banding stations have demonstrated some evidence of wintering site fidelity (usually on a biennial basis) and breeding site fidelity [10, 11, 14-18]. However, our knowledge of the origin of wintering birds or the winter distribution of breeding birds is fragmentary. The only data pertaining to interseasonal movements come from anecdotal observations from a few scattered banding stations $[18,19]$. In this contribution, we analyze all of the banded Purple Finch re-encounters (nearly 20,000 records) to elucidate the interseasonal movements of this vagile species. The data also contribute to our understanding of wintering and breeding site fidelity.

\section{MATERIALS AND METHODOLOGY}

The primary data for this paper are the 19,893 reencounters of Purple Finches in the Bird Banding Lab (BBL) database. The data used span the period from 1921 until 
2008. For each re-encounter, we determined the distance between the banding site and the re-encounter site using a distance calculator [20] The cardinal direction of the movement was also determined.

The BBL uses state or province as a location parameter. We use that system in our analysis.

We divided the year into four seasons based on Purple Finch nesting and movements [9]. Spring was defined as 1 March until 15 April. The breeding season spanned 16 April until 15 August. Fall was defined as 16 August until 30 November. The winter season Start from 1 December until 29 February.

Temporal and spatial differences in banding effort present obstacles in determining patterns of movement with a high degree of quantitative accuracy. Fig. (1A) provides 1960 number for each state or province of the 745,181 Purple Finches banded over the 88 years of this dataset using six equal quantiles to indicate number of Purple Finches banded. Fig. (1B) presents the number of birds banded per year over the same period.

For re-encountered birds, we prepared graphs of the number of all re-encountered birds and the number of reencountered birds excluding local re-encounters over each
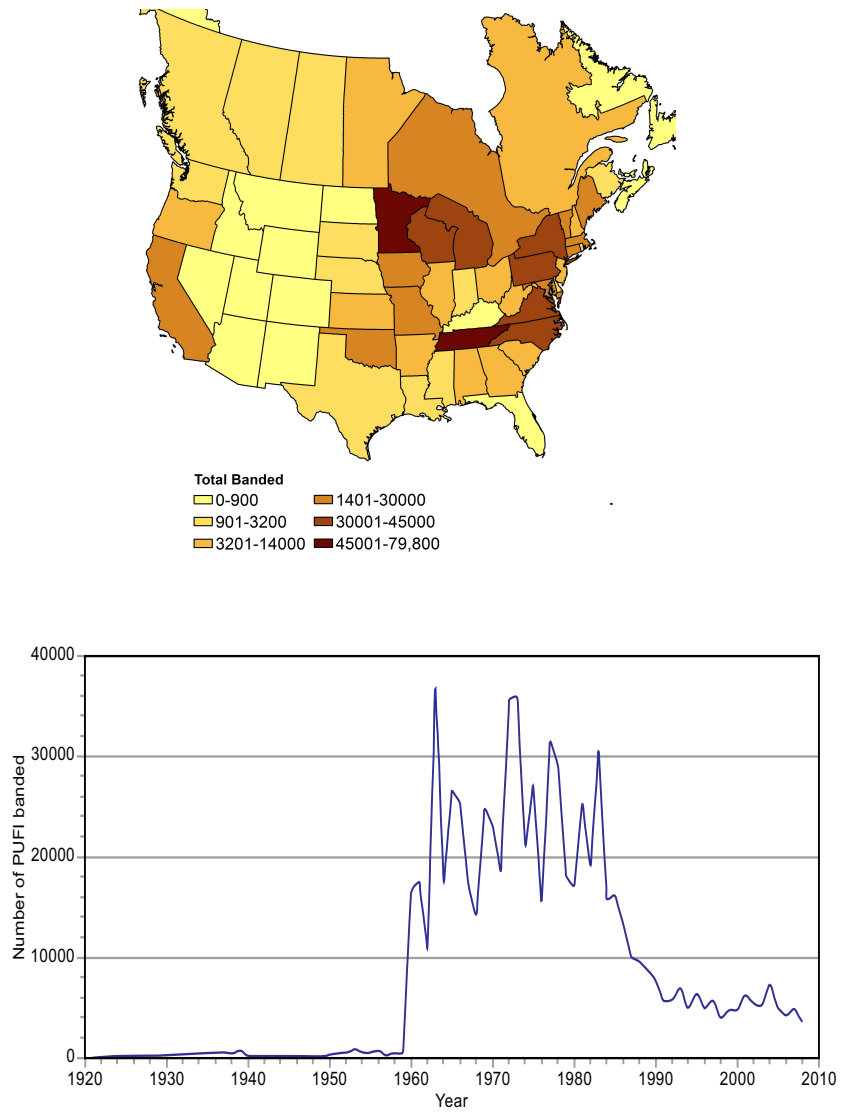

Fig. (1). Spatial and temporal variation in banding of Purple Finches in North America from 1921 until 2008. Fig. (1A) shows the number of birds banded in each state. A color ramp divides the states and provinces into six equal quantiles with the darkest color having the highest value. Fig. (1B) shows the total number of Purple Finches banded in each year. year of the study (Figs. 2A-B). Fig. (2C) presents the percentage of re-encountered birds to total banded birds for each year beginning from 1960 when banding efforts increased dramatically (Fig. 1B).

To determine interseasonal movements of birds, we concentrated on the 12 states with the highest number of birds that were subsequently re-encountered. Ten of these (Maine, New Hampshire, Vermont, Massachusetts, Connecticut, New York, Pennsylvania, Michigan, Wisconsin, and Minnesota) provide breeding as well as winter habitat for Purple Finches. The remaining two states (New Jersey and North Carolina) provide wintering, but not breeding, habitat.

We used ArcGIS to prepare maps for each of the focal states, indicating the state or province where re-encountered birds were captured. To control for differences in banding effort and the size of each state or province, we normalized the data by dividing the number of re-encounters by the percentage of the 745,181 Purple Finches banded in each state

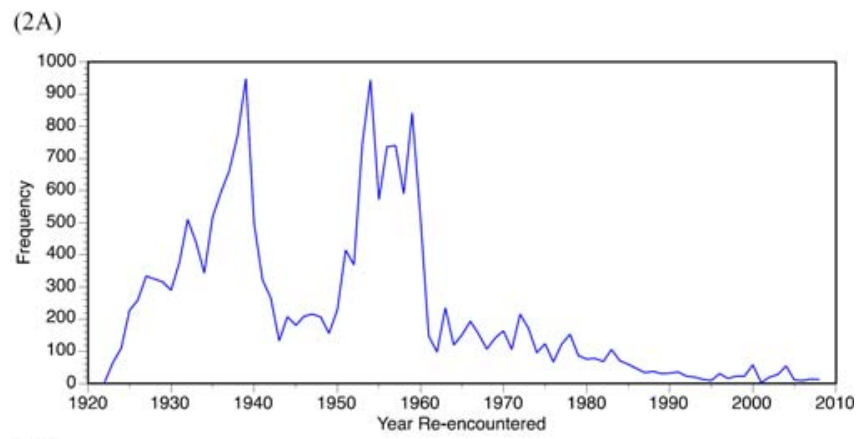

(2B)

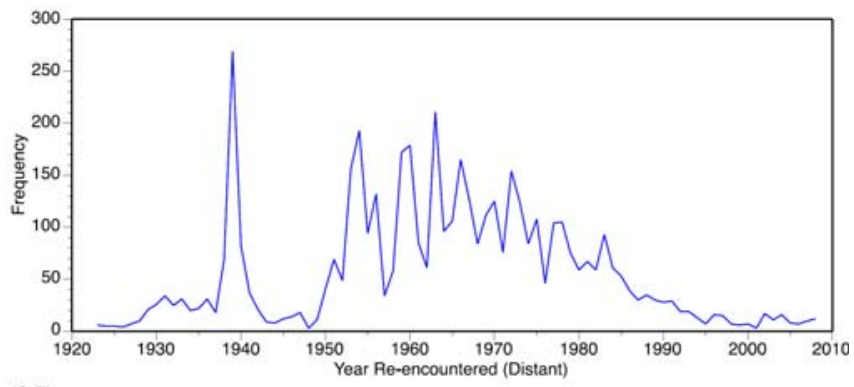

$(2 \mathrm{C})$

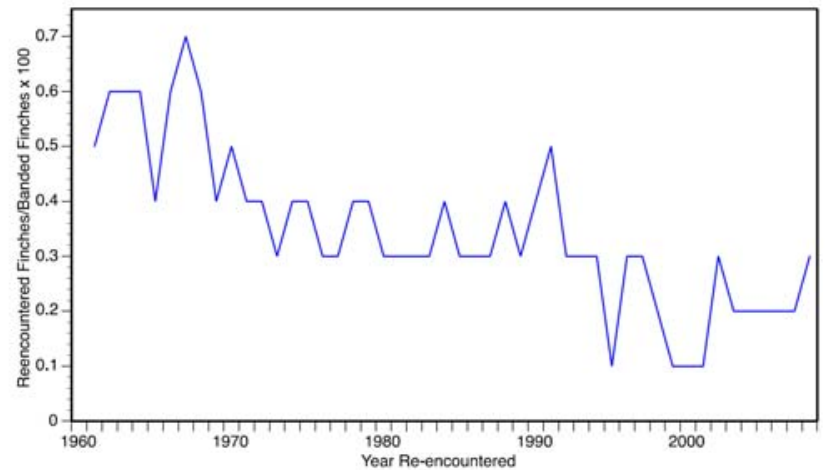

Fig. (2). Temporal variation in re-encounters of Purple Finches. Fig. (2A) presents all re-encounters; Fig. (2B) presents reencounters at sites other than the original banding site. Fig. (2C) presents re-encounters divided by the number of birds banded as a percentage. 
or province. As an example, a Purple Finch re-encountered in Tennessee with very high banding effort has less importance compared to a bird re-encountered in a similar-sized state like Kentucky where banding effort is less. In addition, we divided each number of re-encounters by the area of the state or province to control for differences in geographic area. We used a color ramp of five equal quantiles to represent the normalized re-encounters across North America.

To examine the directionality of the migrations from a banded site, we prepared compass roses using the statistical software, R. The 360 degrees of the compass were divided into equal 30-degree sectors.

To examine breeding site fidelity, we used all the reencounters from the breeding season (16 April - 15 August) from birds that were originally banded in the breeding season in a prior year. The number of years between banding and re-encounter and the distance between the two points was determined. We performed the same type of analysis for wintering birds.

To gain insight into the timing of pulses of movement, we divided the re-encounters into season when each bird was originally banded. All birds re-encountered within 120 days of original banding were excluded (3,025 records). For each season, we used one-way ANOVA using season of reencounter to examine the mean distances moved. Scheffé post-hoc contrasts were used to test for pair-wise differences in means $(\mathrm{p}<0.05)$.

\section{RESULTS}

Fig. (2) presents the temporal distribution of reencounters in the data set. Interestingly, the distribution of banding of Purple Finches (Fig. 1B) is not reflected in the distribution of re-encountered birds (Fig. 2A). Re-encounters were highest in the 1930's when total banding was modest (Fig. 1B). However, many of those re-encounters were birds repeatedly caught locally. When those birds are removed, the distributions of Fig. (1B) and Fig. (2B) are more similar, as one would expect, except for 1939 when banding effort was very high [13]. For the period, 1960-2007, we present the number of re-encounters normalized by the total birds banded that year as a measure of effort. The proportions of banded birds that were re-encountered vary between 0.1 and $0.7 \%$ over the time period.

The geographic distribution of re-encountered birds banded in the northern New England states appears in Fig. (3). The general pattern is that these birds occur broadly, but mostly in the eastern United States. All three states had Purple Finches that wintered in Texas. Modest numbers reached Michigan, Ontario, Wisconsin and Minnesota. Fig. (4) presents data on the trajectories of movements out of each of the three states of all birds re-encountered. The preponderance of movement is to the southwest for each state. Surprisingly, Vermont birds show less pronounced eastward movements even though Vermont is the westernmost of the three states.

Fig. (5) presents the corresponding data for Massachusetts, Connecticut and New York. The first two states show similar patterns to the other New England states with reencounters mostly along the eastern seaboard, curling westward through the Gulf Coast states. The westward location of New York is reflected in higher numbers of re-encounters in the mid-western states. A few birds banded in Connecticut were re-encountered in the western provinces. Fig. (6) shows the pattern of trajectories of movements of all the re-
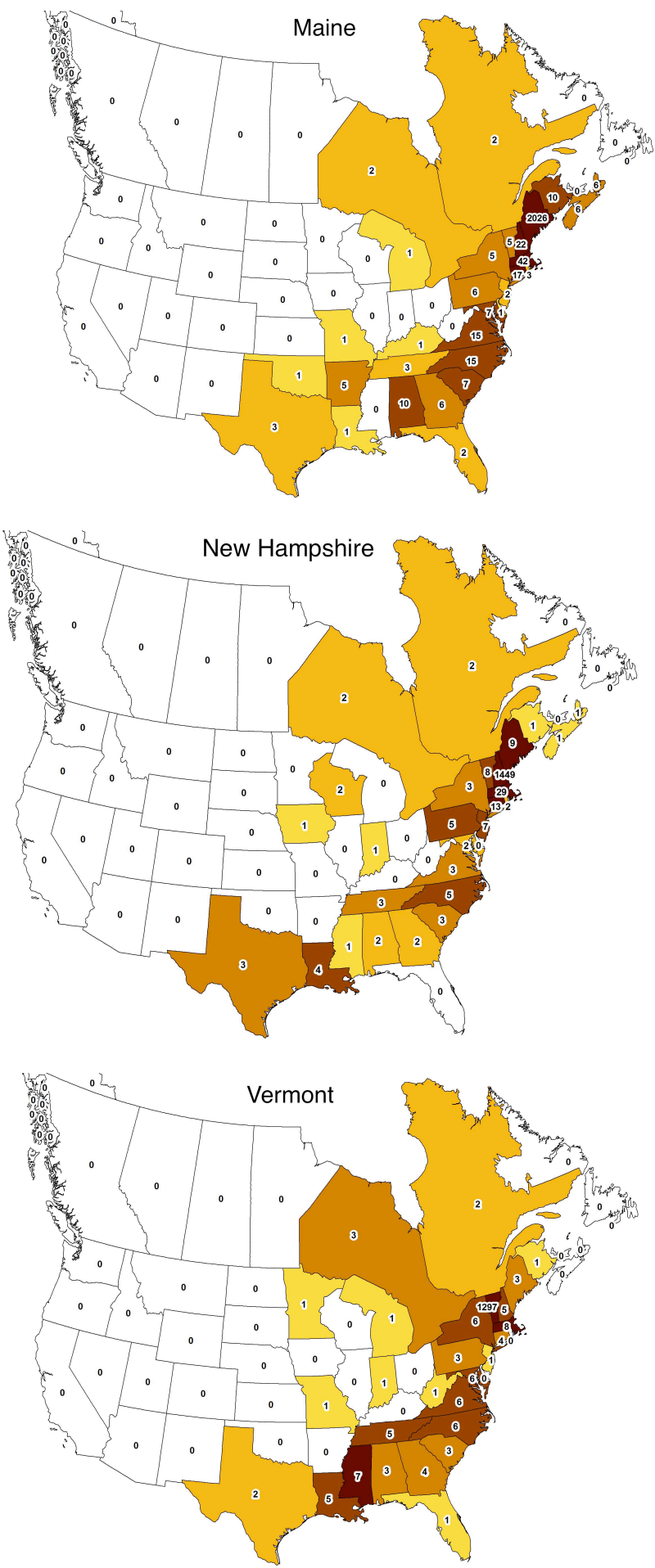

Fig. (3). The distribution of re-encounters of Purple Finches originally banded in Maine, New Hampshire and Vermont. The label at the top of each map represents the state where the original banding occurred. A five-color ramp with equal quantiles (dark is highest) represent the normalized re-encounters. The raw re-encounter data are given as Arabic numbers. 

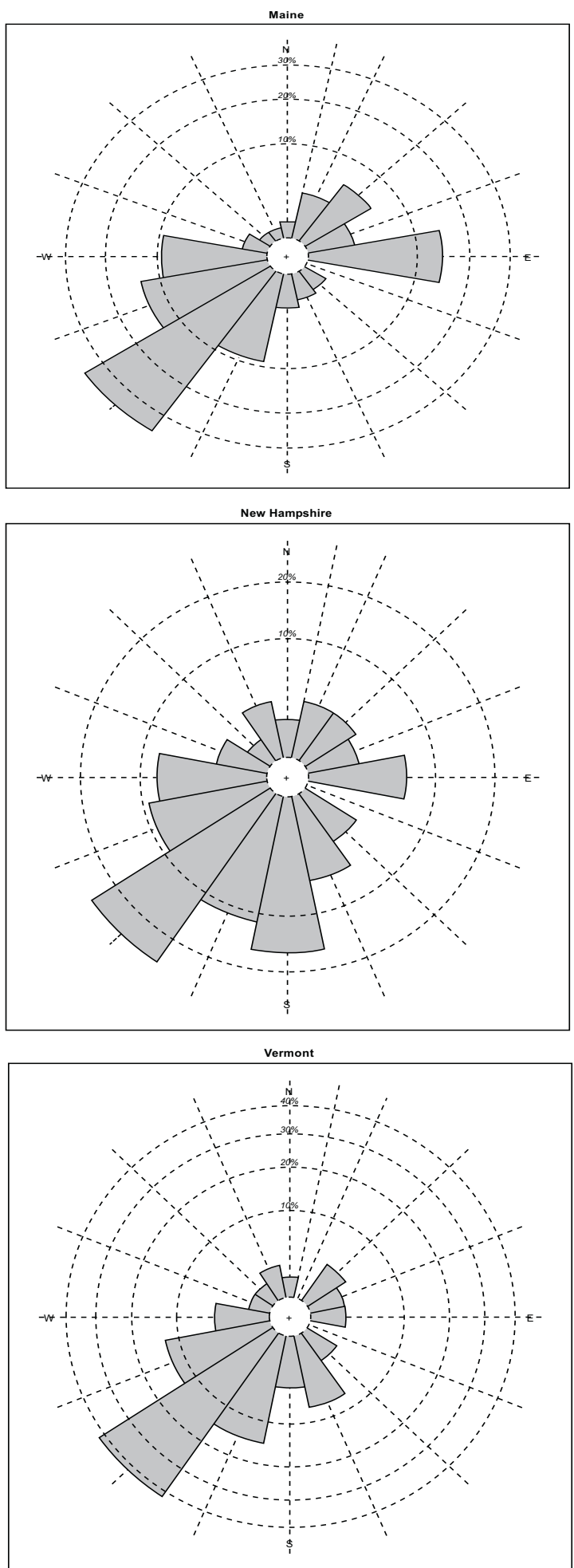

Fig. (4). Compass roses to show direction of movements of reencountered Purple Finches originally banded in each state. Due north is toward the top of the page.

encountered birds out of these three states. Massachusetts has a broad range of movements with slightly more Purple Finches moving to the southwest. Connecticut and New York both show strong movements along a southwest to northeast axis.

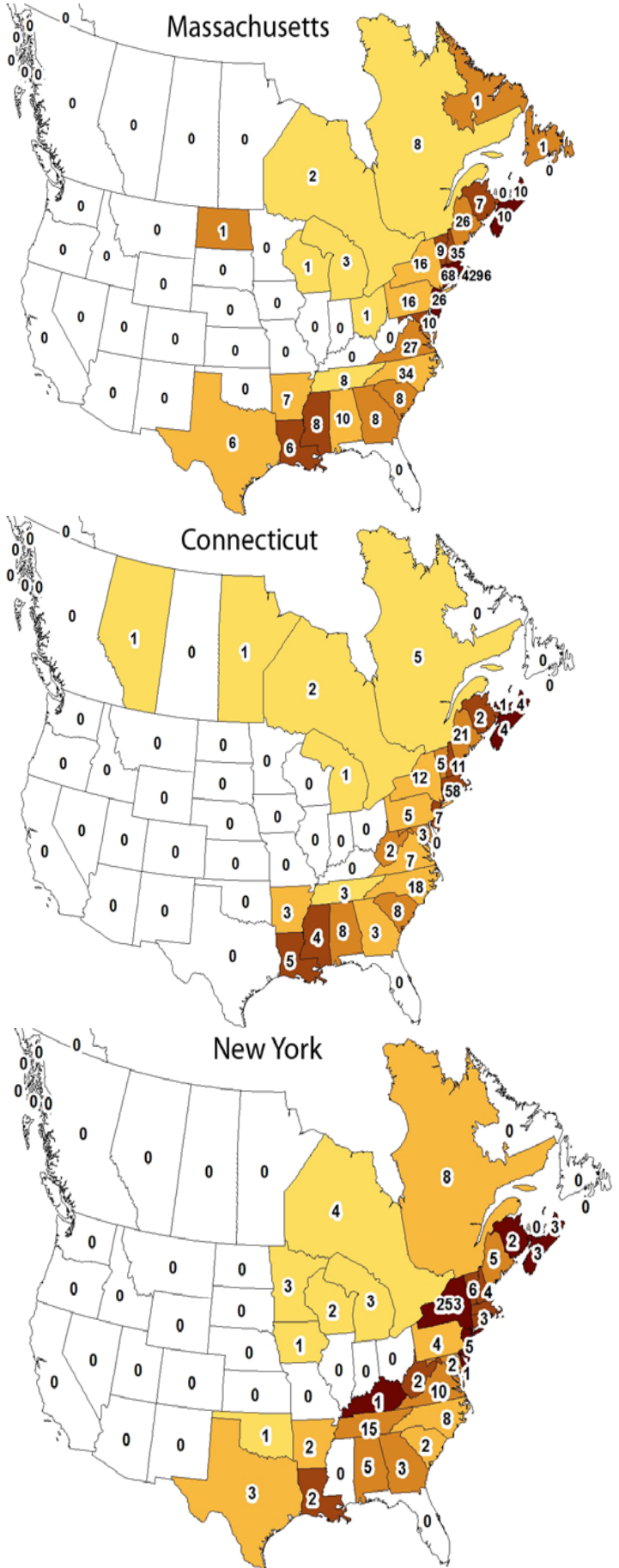

Fig. (5). The distribution of re-encounters of Purple Finches originally banded in Massachusetts, Connecticut and New York. The label at the top of each map represents the state where the original banding occurred. A five-color ramp with equal quantiles (dark is highest) represent the normalized re-encounters. The raw reencounter data are given as Arabic numbers.

The geographic distributions of birds banded in Michigan, Wisconsin and Minnesota are shown in Fig. (7). The three states show different patterns from those in Figs. $(3,5)$. Birds banded in Michigan occurred broadly. Some birds occurred in the western provinces all the way to British Co- 

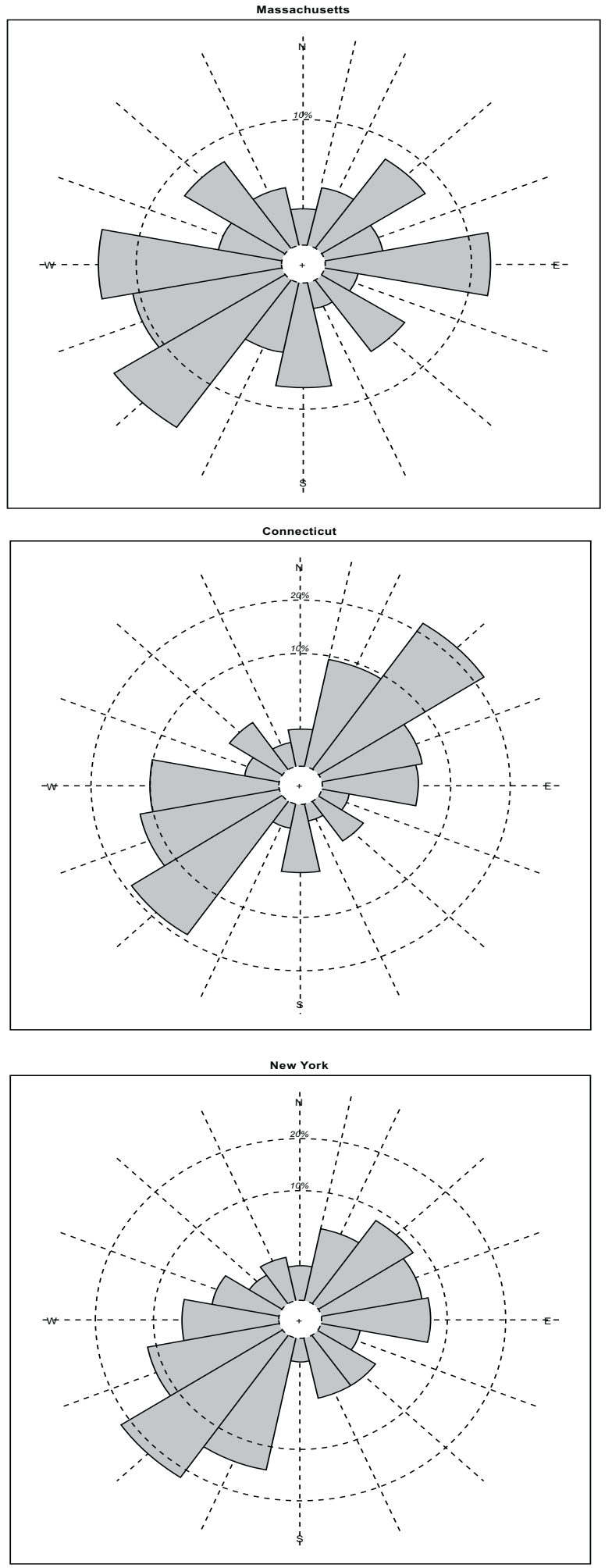

Fig. (6). Compass roses to show the direction of movement of reencountered Purple Finches originally banded in each state.

lumbia. Birds banded slightly west in Wisconsin and Minnesota showed a distinct westward shift when re-encountered. Birds banded in both states were rarely encountered along the eastern seaboard. Heaviest re-encounters were in the mid-western states and the western provinces. A compass rose (Fig. 8) indicates all three states have a distinct ten-
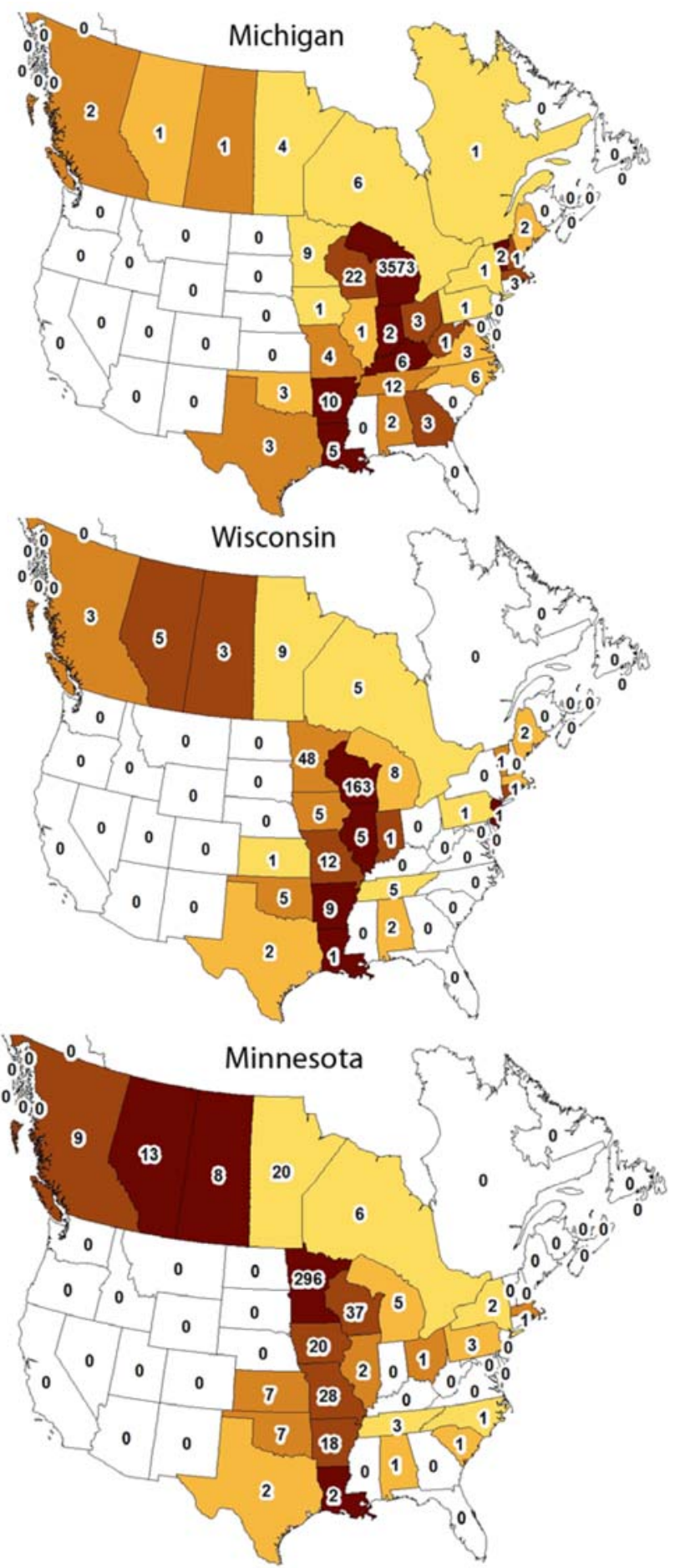

Fig. (7). The distribution of re-encounters of Purple Finches originally banded in Michigan, Wisconsin and Minnesota. The label at the top of each map represents the state where the original banding occurred. A five-color ramp with equal quantiles (dark is highest) represent the normalized re-encounters. The raw re-encounter data are given as Arabic numbers.

dency to move southward, although the predominant general direction of movement from Wisconsin is to the northwest.

Fig. (9) depicts the distribution of re-encounters of birds banded in Pennsylvania, New Jersey and North Carolina. 

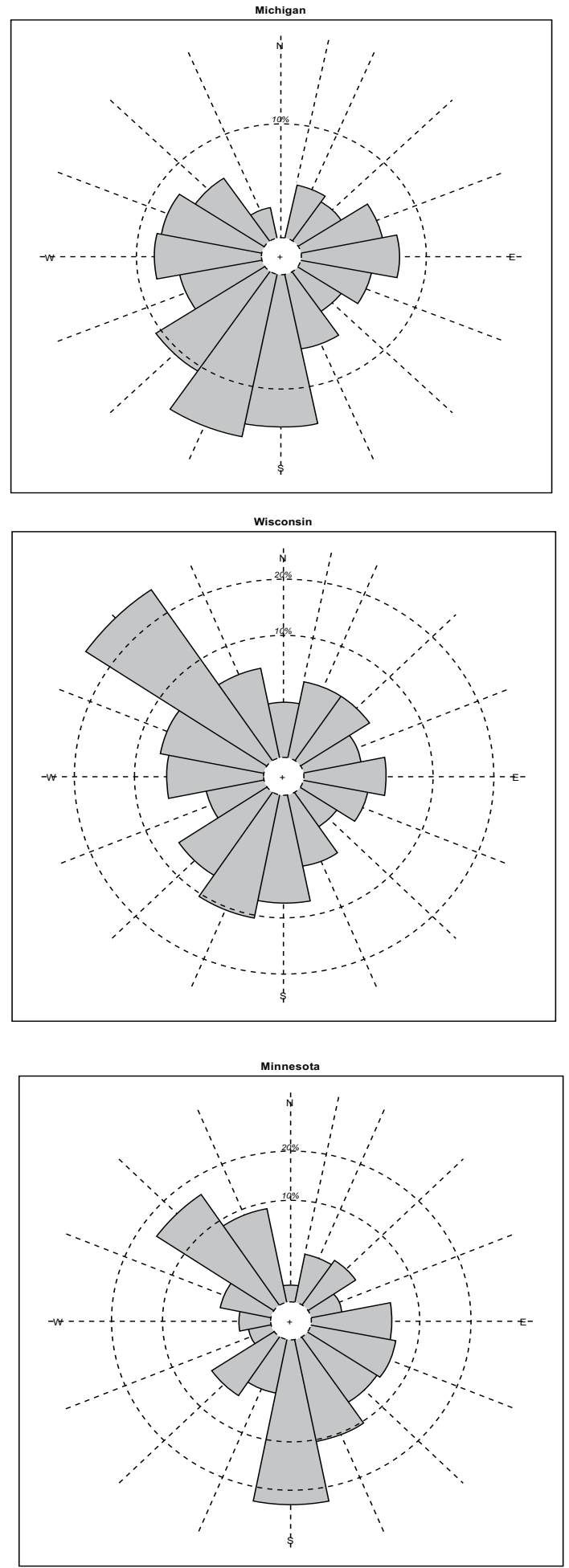

Fig. (8). Compass roses to show direction of movement of reencountered Purple Finches originally banded in each state.

The latter two states are south of the breeding range of Purple Finch. Birds banded in Pennsylvania show a strong eastern seaboard and Gulf coast signature of re-encounters with a few occurring in Ontario, Michigan and Wisconsin. A similar pattern emerges for New Jersey with a few remarkable individuals co-occurring in Alberta and Manitoba. The pattern for North Carolina is consistent with the other eastern
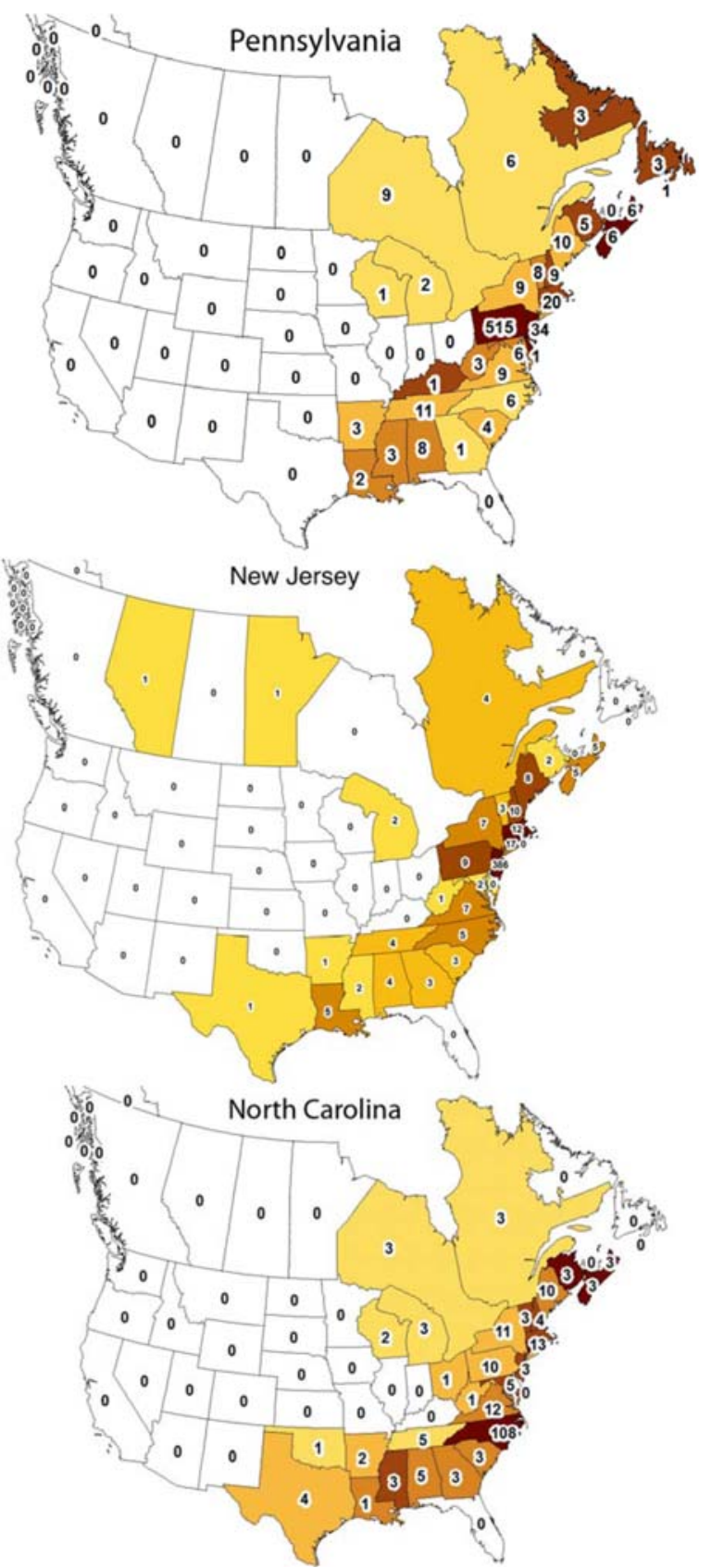

Fig. (9). The distribution of re-encounters of Purple Finches originally banded in Pennsylvania, New Jersey and North Carolina. The label at the top of each map represents the state where the original banding occurred. A five-color ramp with equal quantiles (dark is highest) represent the normalized re-encounters. The raw reencounter data are given as Arabic numbers.

states. Most re-encounters are in Atlantic or Gulf states. Compass roses (Fig. 10) indicate that birds move in all directions with a greater tendency to move to the northeast. Compared to more northerly states, this pattern of movement is similar to Connecticut but dissimilar from Maine, Vermont, Massachusetts, New Hampshire and New York (Figs. 3,5).

The number of re-encounters for the Pacific states and British Columbia is quite limited but worthy of consideration. For birds banded in California, 148 re-encounters have 

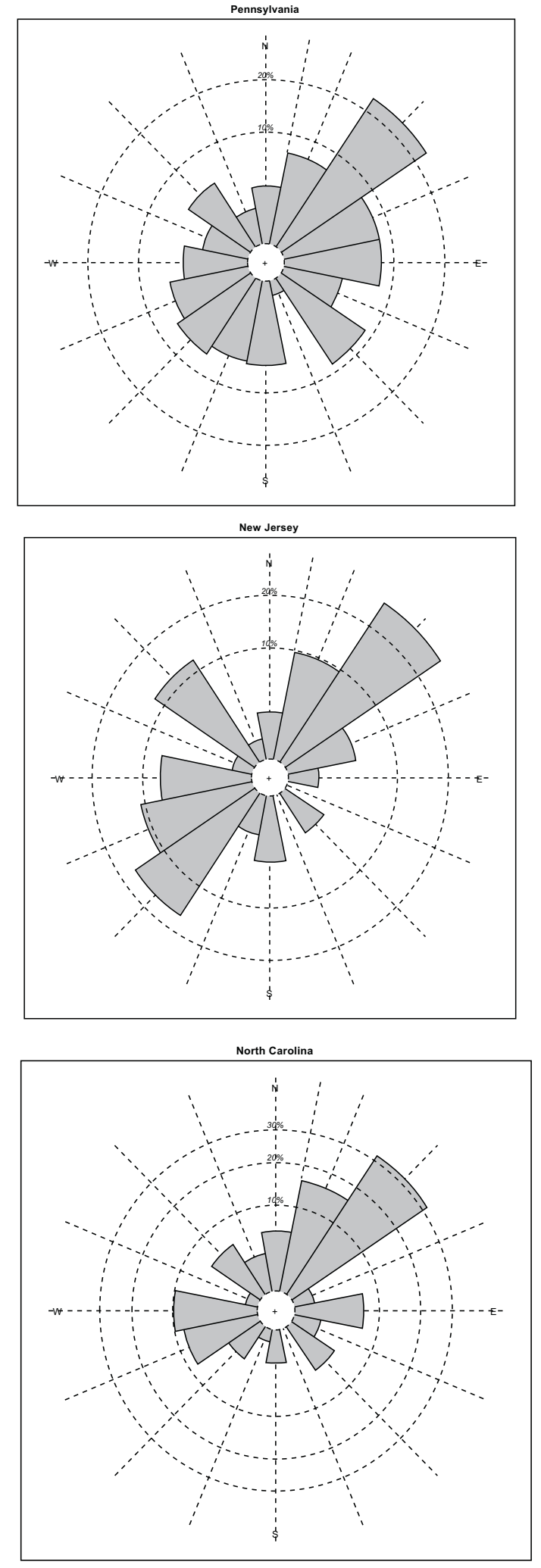

Fig. (10). Compass roses to show distribution of directions of migration for birds banded in a particular state.

been reported. One-hundred-forty of those were also in California with four in Oregon, three in Washington and one in British Columbia. Thirty-six birds banded in Oregon were re-encountered: 25 in Oregon, six in Washington and five in
California. For birds banded in Washington, 40 were reencountered: 33 in Washington, three in Oregon, three in British Columbia and one in California. Of the 55 reencountered birds banded in British Columbia, 53 were found in British Columbia, one in Washington and one in Alberta. Fig. (11) shows compass roses of the trajectories of movement. The general movements are northward and south to southeastward. The eastward movements in British Columbia and Washington are a reflection of most banding being done in the western portion of each area. Eastward movements are possible without a bird leaving the state or province.

Fig. (12) presents data on breeding and winter site fidelity. With unequal banding efforts across space and time, it is impossible to determine a percentage of fidelity with any confidence. However, it is clear from Fig. (12A) (note the logarithmic scale of the y-axis) that breeding site fidelity, in some cases for more than five years, occurs in Purple Finches. The decline in frequency with time between banding and re-encounter is as one would expect. Of the 5,235 reencounters, 4,952 (94.6\%) occurred at the original banding site. Re-locations between $13-100 \mathrm{~km}$ and $100-500 \mathrm{~km}$ from the banding site were about equivalent. Occasionally, a bird relocated to a far distant breeding site.

Fig. (12B) presents similar data for winter site fidelity. The pattern is similar, though not quite as strong, to the pattern for breeding site fidelity. Of the 649 re-encounters in the data set, 443 (68.3\%) were recaptured locally in subsequent years.

We discovered some evidence that some birds may display year-round fidelity, at least for a portion of their lives. To qualify as evidence, a bird had to be banded in the breeding season and then re-encountered at the same location in the wintering season or, conversely, re-encountered during the breeding season after banding during a winter season. Seventy-five birds met these criteria and 15 were reencountered at least twice. Some birds were re-encountered during the fall or spring as well. We list the ten most compelling examples in Table $\mathbf{1}$.

Table 2 presents data on the average distance of reencounters from the original banding site as a function of season re-encountered. We restrict our analysis to birds banded in either the breeding or wintering season as the motility of birds during migration confounds interpretation for birds banded in either the spring or fall. The ANOVA for birds banded in the breeding season (Table 2A) indicates significant differences for birds recovered in each of the seasons $\left(\mathrm{F}_{3,10841}=1391.5, \mathrm{p}<0.001\right)$. Scheffé post hoc contrasts indicate each mean is different from all others. Unsurprisingly, birds re-encountered in the breeding season in subsequent years show the lowest mean distance. Fall distances are the next smallest distance, followed by spring and lastly winter.

The comparable data for birds banded in the winter season are presented in Table (2B). The ANOVA indicates significant differences among seasons $\left(F_{3,1990}=63.04, p<\right.$ 0.001). However, post hoc Scheffé contrasts indicate that the means for spring, winter and fall are not different from each 

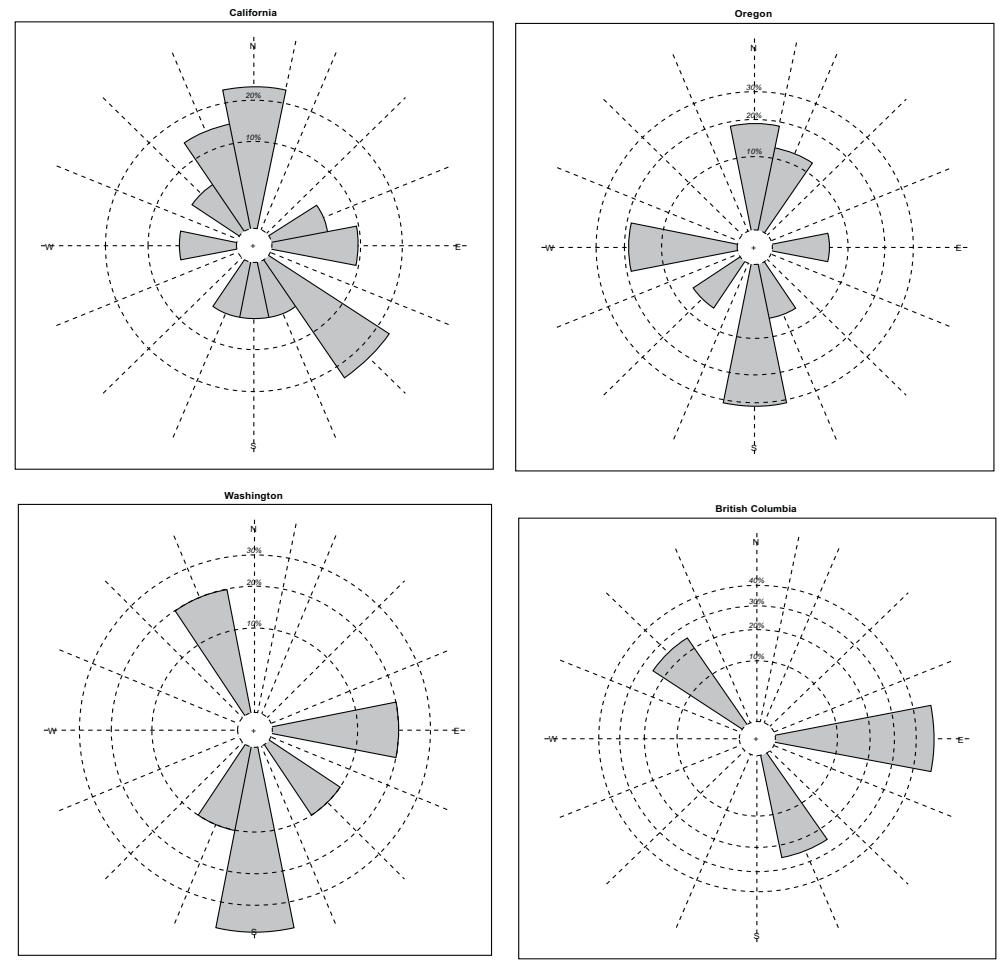

Fig. (11). Compass roses for movements of Purple Finches in four Pacific province/states.

(a)

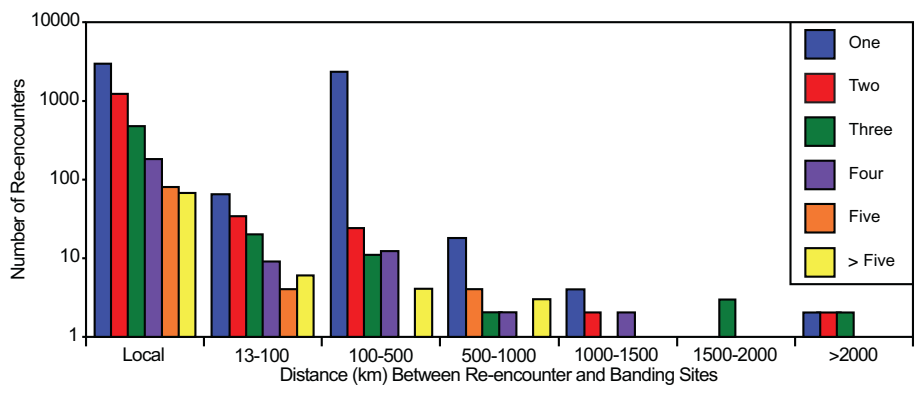

(E)

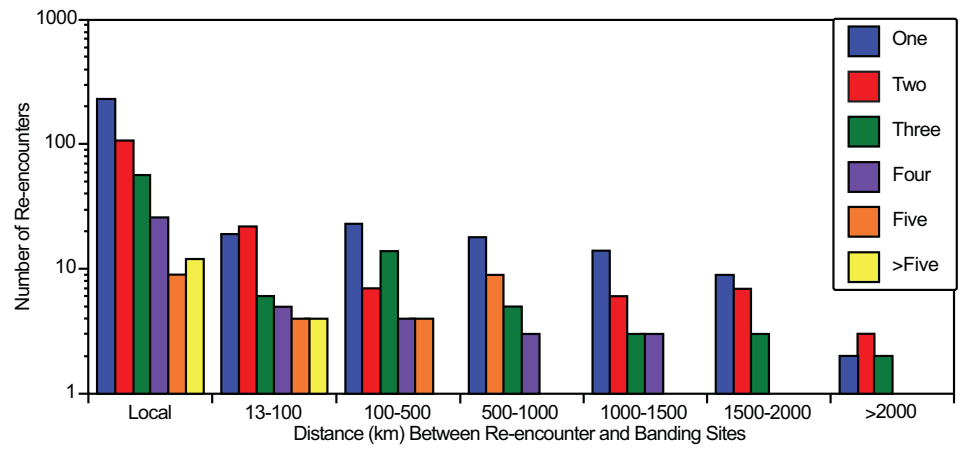

Fig. (12). Fig. (12A) presents the frequency of re-encounters of birds banded during the breeding season and re-encountered in a subsequent breeding season. Different colors of bars represent different numbers of years between banding and re-encounter for seven different ranges of distance. Fig. (12B) presents the corresponding data for birds banded during the winter and re-encountered during a subsequent winter. Note that the y-axis has a logarithmic scale.

other. All three are significantly smaller than the mean for the breeding season.

Taken together, the data indicate that birds tend to linger well into the fall after breeding (Table 2A) and that birds tend to arrive and depart from their wintering grounds fairly quickly (Table 2B).

Extreme occurrences are often of interest. For Purple Finches, the maximum distance between captures was for a bird banded in Maine on 5 May 1966 and re-encountered in 
Table 1. Evidence of Year-round Fidelity. Birds Were Either Banded During the Breeding Season and then Re-encountered at Least Once During the Wintering Season at the Same Locality or Banded During the Wintering Season and Reencountered at Least Once During the Breeding Season

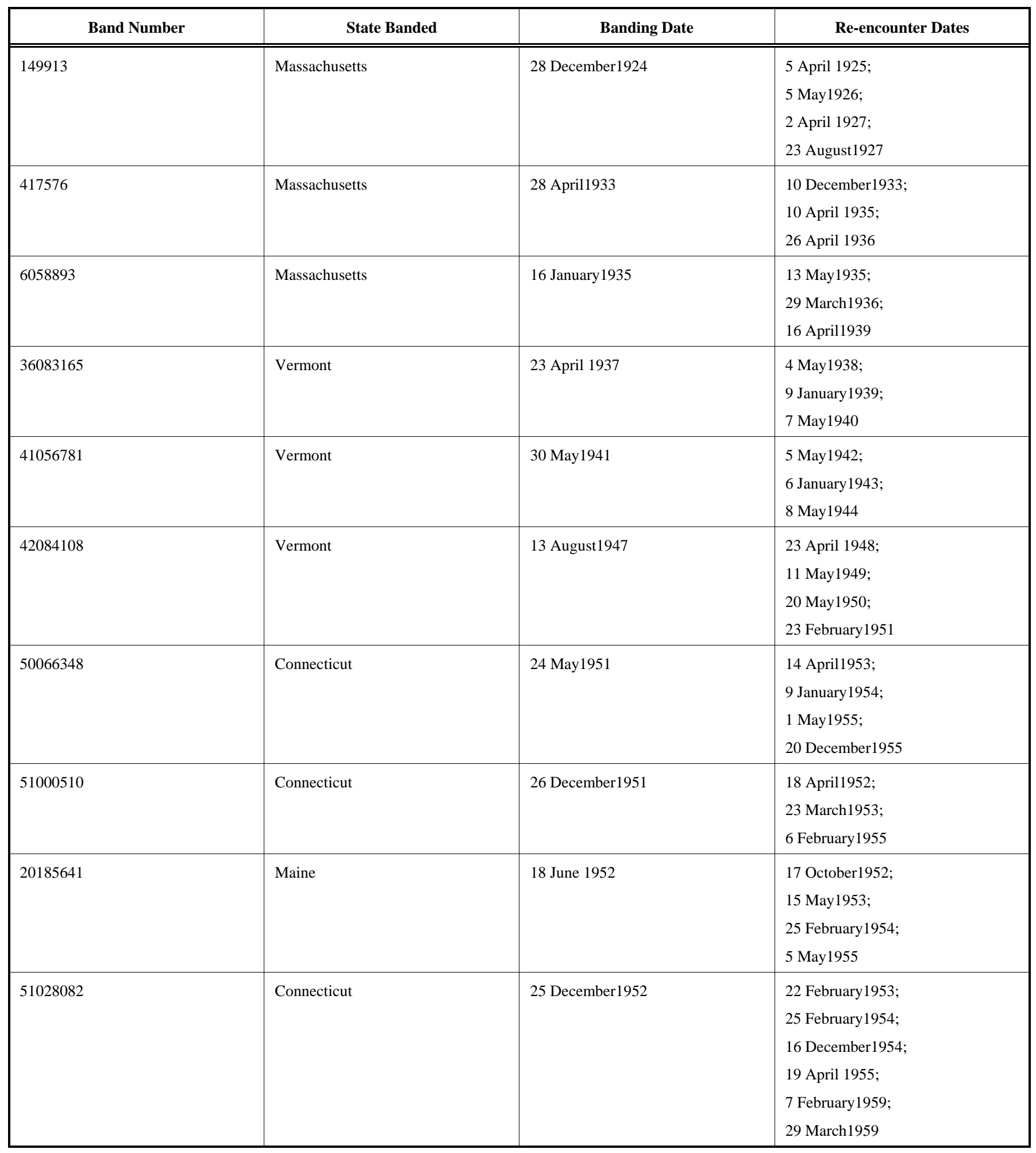

Texas on 23 December 1988, a distance of $2884 \mathrm{~km}$. The mean distance traveled was $504 \mathrm{~km}$ excluding all local reencounters or $122 \mathrm{~km}$ for all re-encounters.
Three particularly noteworthy data notably extend the previous longevity record (14 years) for the species [21]. A bird banded in Vermont on 7 September 1981 and reencountered in Florida on 19 October 2003 was 22.1 years old. A bird banded in Minnesota on 19 April 1963 was re- 
Table 2. Mean Distances (km) Traveled of Birds Re-encountered After Banding During the Breeding Season (A) and During the Winter Season (B) as a Function of Re-encounter Season. All Birds Re-encountered Within 120 Days of Initial Banding Were Excluded from the Analysis. Data are Presented as Mean (Standard Deviation). Letters to the Right of Each Mean Indicate Results of Scheffé Post-hoc Contrasts; Means Sharing the Same Letter not Statistically Different $(p>0.05)$

A. Birds Banded During the Breeding Season

\begin{tabular}{|c|c|c|c|c|}
\hline Season Re-encountered & Breeding & Fall & Winter & Spring \\
\hline \hline & $11.7 \mathrm{a} \mathrm{(103.6)}$ & $60.0 \mathrm{~b}(233.5)$ & $697.0 \mathrm{c}(733.9)$ & $164.8 \mathrm{~d}(384.3)$ \\
\hline
\end{tabular}

B. Birds Banded During the Winter

\begin{tabular}{|c|c|c|c|c|}
\hline Season Re-encountered & Winter & Spring & Breeding & Fall \\
\hline \hline & $197.8 \mathrm{a}(440.8)$ & $190.5 \mathrm{a}(384.3)$ & $584.9 \mathrm{~b}(720.2)$ & $229.8 \mathrm{a}(486.8)$ \\
\hline
\end{tabular}

encountered on 18 March 1984, 20.9 years later. A finch banded on 11 August 1928 was re-encountered in Pennsylvania on 15 June 1946, 17.9 years later.

\section{DISCUSSION AND CONCLUSION}

The Purple Finch is a vagile species restricted to North America. Based on the number of birds captured at continuously operated banding stations, a strong biennial cycle of irruptions of Purple Finches south of their breeding range has been documented [12, 22]. The generality of this pattern is borne out by Christmas Bird Count data and Project FeederWatch data. This pattern has been attributed to alternate year failure of cone crops of conifers in the breeding range of the Purple Finch [23]. We know of no direct support of this cone-failure hypothesis. The hypothesis that Purple Finch irruptions are being short-stopped in recent years because of the prevalence of bird feeders is not supported, thus failing to provide indirect evidence for food limitation in this species [24].

Despite the claim that Purple Finches do withdraw from their northern breeding areas in alternate years, little information is available about the behavior of individual birds. Re-encounter of banded birds provides a mechanism to understand movements of individual birds. However, great variability in banding effort over time and space (Figs. 1,2) makes it difficult to determine meaningful rates of movements. By normalizing re-encounter frequency by banding effort and by size of the geographic unit, we have reduced some of this inherent variability. Our analysis (Figs. 3-6) indicates that birds in the Maritime Provinces and New England move largely along a north-south axis with some movement westward to Gulf Coast states. Birds in the Midwest mostly follow a north-south axis as well with birds banded in Minnesota and Wisconsin rarely occurring along the eastern seaboard. Limited data exist for the Pacific coast states and British Columbia, but only one bird banded in any of these four areas has been re-encountered outside the region. A single Purple Finch re-encountered in Alberta is the only one of 275 re-encountered birds originally banded in the three states or British Columbia.

Data from individual banding stations had previously identified varying degrees of winter site fidelity. For a site in Tennessee, the return rate was $1.1 \%$ [25]. A slightly higher winter recovery rate $(1.6 \%)$ was found for a different site in
Tennessee [26]. For a site in Hillsborough, North Carolina, winter fidelity rates between $8.9 \%$ and $21.6 \%$ over seven winters were reported [19]. At a banding station in Schenectady, NY, 0.5\% of 2,822 Purple Finches banded over an 18-year period were re-encountered in subsequent years [16]. Anecdotal evidence exists for winter site fidelity to a banding station in South Carolina [18]. Twenty-six Purple Finches banded in previous winters returned to the banding site. Eighteen of those returned for the first time. Five returned for a third winter and three returned for their fourth winter. Using all of the winter re-encounters of birds banded in previous winters, we were able to demonstrate much stronger winter site fidelity than heretofore demonstrated (Fig. 7A). Over 68\% of the re-encounters were made at the original banding site.

Breeding site fidelity has received less attention by individual banders. In Michigan, a fidelity rate of $56.8 \%$ to breeding sites was observed [14, 22, 27]. Breeding site fidelity of $23.6 \%$ was reported from Schenectady, New York [16, 17]. Our analysis indicates very strong fidelity with over $94 \%$ of breeding season re-encounters occurring at the original banding site for birds banded during a previous breeding season.

As shown in Table 1, some Purple Finches show evidence of year-round fidelity. To detect such behavior, a banding station must be operated continuously for at least several years. We have no way to know how many continuously operated stations failed to detect such year-round fidelity. Therefore, we cannot determine how frequently such year-round fidelity occurs although it certainly must apply to a minority of Purple Finches.

The analysis of the relationship of distance traveled between original banding and re-encounter as a function of season (Table 2) provides some insight into the pace of annual movements. Birds banded on the breeding grounds (Table 2A) did not stage much movement until the winter. They did show northward movements in the spring. For birds banded on the wintering grounds, little movement occurs over the spring and then the greatest movement occurs as they migrate to the breeding grounds (Table $\mathbf{2 B}$ ).

In conclusion, the re-encounter data indicate that Purple Finches tend to follow a north-south axis of movement for birds in northeastern North America, in the Midwest and long the Pacific coast. We can detect breeding site fidelity, wintering site fidelity and, less frequently, year-round site 
fidelity but uneven banding effort thwarts any effort to know how frequently these behaviors arise. Birds tend to linger on the breeding grounds well past the nesting season and depart from the wintering grounds early in the spring. By using the rich data from the Bird Banding Laboratory, we are able to make a significant contribution by linking the winter and breeding season ranges of a representative passerine.

\section{CONFLICT OF INTEREST}

The author(s) confirm that this article content has no conflicts of interest.

\section{ACKNOWLEDGEMENTS}

We are grateful to Danny Bystrak of the Bird Banding Laboratory for making the banding records available. We wish to thank Manny Gimond, Colby College, for his assistance in preparing the maps with ARC-Gis and R. Support for this research came from the Leslie Brainerd Arey Research Fund, Colby College.

\section{REFERENCES}

[1] Alerstam T. Bird migration. Cambridge: Cambridge University Press 1990.

[2] Berthold P, Gwinner E, Sonnecschein E, Eds. Avian migration. Berlin: Spring-Verlag 2003.

[3] Newton I. The migration ecology of birds. Amsterdam: Elsevier Press 2008.

[4] Nice MM. Studies in the life history of the song sparrow. New York: Linnaean Society of New York 1937.

[5] Greenwood PJ, Harvey PH. The natal and breeding dispersal of birds. Annu Rev Ecol Syst 1982; 13: 1-21.

[6] Bollinger EK, Gavin TA. The effects of site quality of breeding-site fidelity in Bobolinks. Auk 1989; 106: 584-94.

[7] Kricher JC, Davis WC Jr. Returns and winter-site fidelity of North American migrants banded in Belize, Central America. J Field Ornithol 1986; 57: 48-52.

[8] Wunderlee JM Jr, Latta SC. Winter site fidelity of Neartic migrant in shade grown coffee plantations of different sizes in the Dominican Republic. Auk 2000; 117: 596-614.
[9] Wootton JT. Purple Finch (Carpodacus purpureus). In: Poole A, Gill F, Eds. The Birds of North America, No. 208. Philadelphia: The Academy of Natural Sciences; Washington D.C: American Ornithologists' Union 1996; pp. 1-24.

[10] Blake CH. Further notes on Purple Finches. Bird-Banding 1962; 33: 173-80.

[11] Blake CH. Purple finches at Hillsborough: NC, 1961-1965. BirdBanding 1967; 38: 1-17.

[12] Kennard JH. Biennial rhythm in Purple Finch migration. BirdBanding 1977; 46: 55-73.

[13] Weaver RL. The purple finch invasion of northeastern United States and the Maritime Provinces. Bird-Banding 1940; 11: 79-105.

[14] Magee MJ. The average age of the eastern purple finch: an estimate based on returns and recoveries. Bird-Banding 1936; 7: 161-2.

[15] Laskey AR. A longevity and round trip record of purple finches. Bird-Banding 1963; 34: 227.

[16] Yunick RP. Winter site fidelity of some northern finches (Fringillidae). J Field Ornithol 1983; 54: 254-8.

[17] Yunick RP. Seven multiple-recapture encounters with banded birds. Am Bird Bander 1987; 12: 60-3.

[18] Hilton Jr B. Carpodacus finches in South Carolina's Piedmont: migration, sex ratios, site fidelity, and longevity. N Am Bird Bander 1995; 19: 1-11.

[19] Magee MJ. Eastern purple finch recoveries in and away from the eastern part of the upper peninsula of Michigan. Bird-Banding 1935; 6: 102-3.

[20] Williams E. Great circle calculator [homepage on the Internet]. [Cited $19^{\text {th }}$ Dec 2011]. Available from: http://williams.best.vwh. net/agccalc.htm

[21] Kennard JH. Longevity records of North American birds. N Am Bird Bander 1975; 46: 55-73.

[22] Magee MJ. Summary of trapping and banding operations of northern Michigan. Wilson Bull 1926; 38: 162-7.

[23] Bock CE, Lepthien LW. Synchronous irruptions of boreal seedeating birds. Am Nat 1976; 110: 559-71.

[24] Wilson Jr WH. Bird feeding and irruptions of northern finches: are migrations short-stopped? N Am Bird Bander 1999; 24:13-21.

[25] Laskey AR. Longevity and movements of banded Purple Finches. Migrant 1974; 41: 73-4.

[26] Stedman SJ. Return and recovery rates for purple finch banded in Williamson County, Tennessee. N Am Bird Bander 1989; 14: 86-7.

[27] Magee MJ. Note on the purple finch (Carpodacus purpureus purpureus). Auk 1924; 41: 606-10.

(C) Wilson and Brown; Licensee Bentham Open.

This is an open access article licensed under the terms of the Creative Commons Attribution Non-Commercial License (http://creativecommons.org/licenses/by$\mathrm{nc} / 3.0 /$ ), which permits unrestricted, non-commercial use, distribution and reproduction in any medium, provided the work is properly cited. 